\title{
Comparison of sea-ice extent and ice-edge location estimates from passive microwave and enhanced-resolution scatterometer data
}

\author{
Walter N. MEIER, Julienne STROEVE \\ National Snow and Ice Data Center, Cooperative Institute for Research in Environmental Sciences, Campus Box 449, \\ University of Colorado, Boulder, CO 80309-0449 USA \\ E-mail: walter.meier@colorado.edu
}

\begin{abstract}
Passive microwave sea-ice concentration fields provide some of the longest-running and most consistent records of changes in sea ice. Scatterometry-based sea-ice fields are more recently developed data products, but now they provide a record of ice conditions spanning several years. Resolution enhancement techniques applied to scatterometer fields provide much higher effective resolutions $(\sim 10 \mathrm{~km})$ than are available from standard scatterometer and passive microwave fields $(25-50 \mathrm{~km})$. Here we examine ice-extent fields from both sources and find that there is general agreement between scatterometer data and passive microwave fields, though scatterometer estimates yield substantially lower ice extents during winter. Comparisons with ice-edge locations estimated from AVHRR imagery indicate that enhanced scatterometer data can sometimes provide an improved edge location, but there is substantial variation in the results, depending on the local conditions. A blended product, using both scatterometer and passive microwave data, could yield improved results.
\end{abstract}

\section{INTRODUCTION}

Sea ice plays an important role in the climate system due to its high albedo relative to the underlying ocean, its impact on heat and moisture transport between the ocean and atmosphere, and its effect on the near-surface freshwater flux. The presence of sea ice also impacts wildlife and human activities in the polar regions. Surface ships or submarines sailing in or near ice-infested waters require knowledge of ice location and conditions for safe transport. Operational sea-ice centers support navigation by providing accurate and timely analyses of ice conditions to military and commercial interests using the best information available at the time of the analyses.

Because of its broad spatial coverage and high spatial/ temporal variability, sea ice is most effectively monitored via satellite remote-sensing instruments. Sea ice is generally distinct from the surrounding open water in imagery from most satellite Earth observation sensors, including visible/ infrared (e.g. Meier, 2005), passive microwave (e.g. Eppler and others, 1992), synthetic aperture radar (SAR; e.g. Heinrichs and others, 2006) and scatterometry (e.g. Onstott, 1992), all of which have been employed to estimate ice cover. Visible/infrared and SAR imagery provide the highest spatial resolution and the most detail on ice conditions for operational analyses. However, their coverage is limited due to sky conditions (clouds, sunlight for visible/infrared) or satellite orbit and sensor parameters (i.e. swath width, ground track repeat interval for SAR). Thus such imagery may not be available in a timely manner.

Passive microwave sensors and scatterometers have a distinct advantage over other instruments because they can monitor ice in all-sky conditions (i.e. without sunlight and in the presence of clouds) and obtain near-complete daily coverage of all sea-ice-covered regions (e.g. Eppler and others, 1992; Onstott, 1992). An important limitation of both passive microwave sensors and scatterometers is their low spatial resolution $(25-50 \mathrm{~km})$. This limits their effectiveness in obtaining a precise ice edge - essential knowledge for operational analyses supporting vessels operating in or near the ice. Passive microwave and scatterometer sensors are similar, in that both obtain information in the microwave part of the electromagnetic spectrum. However, passive microwave sensors detect natural emission from the Earth, while scatterometers are active sensors that measure the backscatter from a signal emitted by the sensor. Thus, these two approaches yield differing information from the ice cover depending on the ice surface characteristics, such as melt or snow cover, which may be revealed as differences within in the ice-extent fields.

\section{PASSIVE MICROWAVE AND SCATTEROMETER DATA}

Passive microwave sea-ice estimates are one of the longest satellite-based environmental records, with a consistent product since late 1978 from the Nimbus-7 Scanning Multichannel Microwave Radiometer (SMMR) and a continuing series of US Defense Meteorological Satellite Program (DMSP) Special Sensor Microwave Imagers $(\mathrm{SSM} / \mathrm{I})$. This study uses a time series of sea-ice concentration, 'Sea Ice Concentrations from Nimbus-7 SMMR and DMSP SSM/I Passive Microwave Data' (D.J. Cavalieri and others, http://nsidc.org/data/nsidc-0051.html), based on the NASA Team algorithm (Cavalieri and others, 1984); the product is archived at the US National Snow and Ice Data Center (NSIDC). Intercalibration using sensor overlaps has been implemented to provide consistency through the time series. Additional quality-control measures are also employed, including spatial and temporal interpolation to fill data gaps, a coastal filter to remove erroneous ice near land, weather filters to eliminate false ice over the ocean, and a sea surface temperature mask to remove any remaining false ice not detected by the weather filters (Cavalieri and others, 1999). The concentration fields are gridded on the NSIDC polar stereographic projection (tangent at $70^{\circ}$ latitude) with a spatial resolution of $25 \mathrm{~km}$.

Scatterometry is a more recent technology than passive microwave sensing, especially in its application to sea ice. Other than the brief ( 3 month) operational lifetime of the 

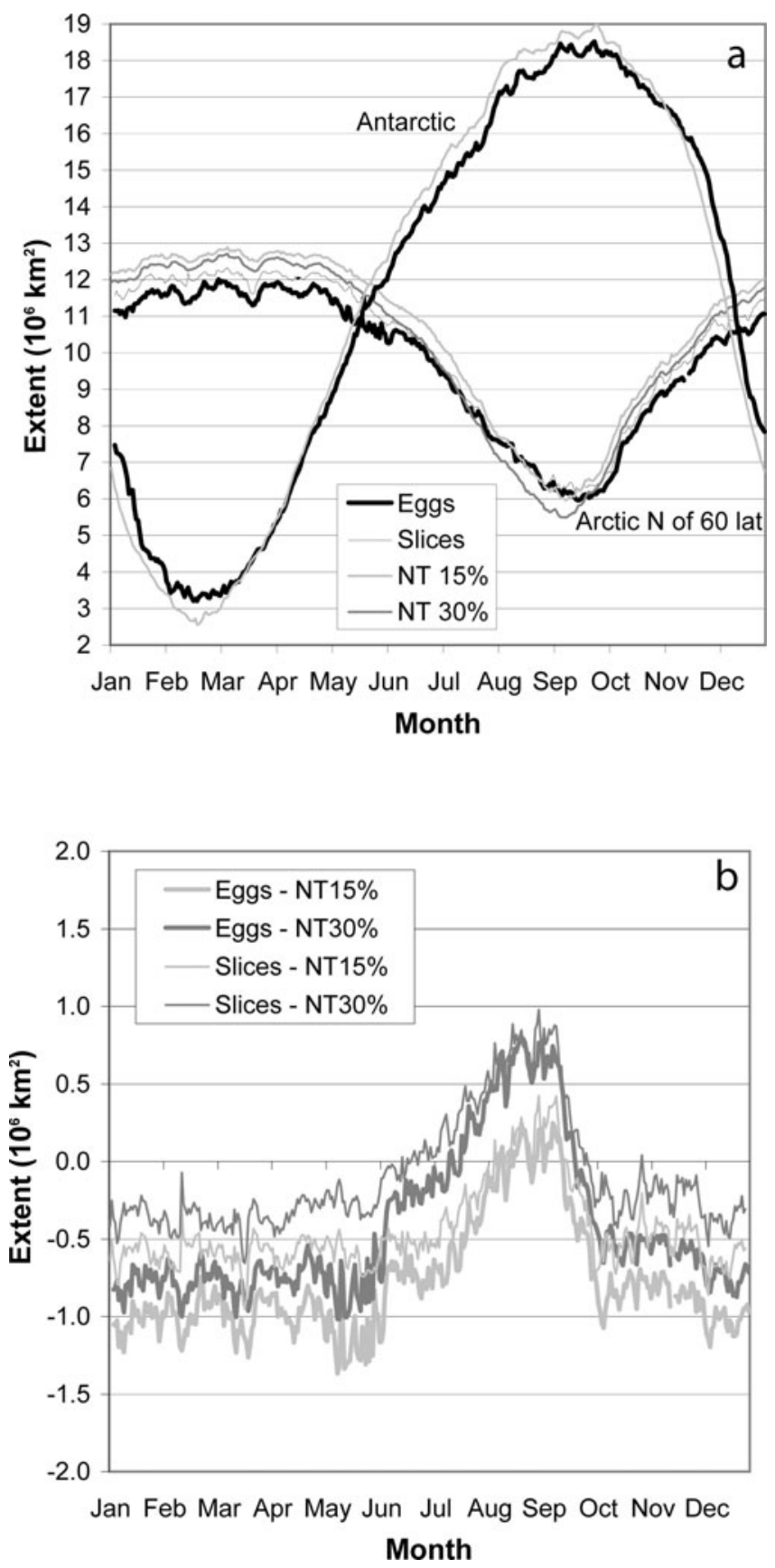

Fig. 1. (a) Annual cycle for the year 2000 of sea-ice extent. Arctic plot contains QuikSCAT eggs/slices and SSM/I NASA Team (NT) 15\% and 30\% edges; Antarctic plot contains QuikSCAT eggs and SSM/I NT 15\% edge. (b) Time series of difference between QuikSCAT and SSM/I Arctic sea-ice extents for 2000.

Seasat scatterometer in 1978, satellite scatterometers did not begin operating until the early 1990s, with intermittent research-level missions such as the NASA Scatterometer (NSCAT), which operated for 9 months beginning in 1996. Since mid-1999, with the launch of the SeaWinds instrument on the NASA QuikSCAT satellite, continuous daily coverage and routine scatterometer data products have become possible. The QuikSCAT data have a nominal field of view comparable to the passive microwave instruments (25-50 km) (Remund and Long, 2000). However, because of the wide-swath $(1800 \mathrm{~km})$ and frequent overpasses in the polar regions, data from multiple passes can be combined to obtain enhanced-resolution fields. QuikSCAT obtains raw backscatter (sigma-0) data in two modes: 'slices' and 'eggs'. Slices are 4-6 km long (along-track) by $20 \mathrm{~km}$ wide (crosstrack). Slices are summed into 'eggs' of $\sim 20 \mathrm{~km}$ by $30 \mathrm{~km}$, depending on the antenna beam and instrument mode.

The resolution enhancement technique, called the Scatterometer Image Reconstruction with Filtering (SIRF) algorithm (Long and others, 1993; Early and Long, 2001), was applied to QuikSCAT data by the Microwave Earth Remote Sensing group at Brigham Young University (BYU), UT, USA (Remund and Long, 2000). The SIRF algorithm is applied to both egg and slice data. SIRF yields slice fields with $2.225 \mathrm{~km}$ gridded resolution and an estimated effective resolution of $\sim 4 \mathrm{~km}$. Enhanced egg fields have a gridded resolution of $4.45 \mathrm{~km}$, with an estimated effective resolution of $\sim 8-10 \mathrm{~km}$. Though the slice fields are at a finer resolution, they are 'noisier' than the egg fields.

Sea-ice extent is estimated from the SIRF backscatter images based on polarization ratio, incidence angle and backscatter standard deviation (Remund and Long, 1999); filtering techniques are used to reduce misclassification noise. The egg and slice fields are processed slightly differently to obtain consistent ice extents from each. The QuikSCAT ice-extent fields encompass the Arctic poleward of $60^{\circ} \mathrm{N}$ and the Antarctic poleward of $52^{\circ} \mathrm{N}$. Thus, during winter, a large part of the ice-covered region in the Arctic (e.g. parts of Hudson Bay, the Bering Sea, the Sea of Okhotsk and the Labrador Sea) is not included in the fields. Both egg and slice QuikSCAT extent fields are archived by NSIDC on a subset of the NSIDC polar stereographic sea-ice grid at their respective gridded spatial resolutions; the QuikSCAT fields are also available through the NASA Scatterometer Climate Record Pathfinder at BYU.

The archived QuikSCAT extent fields were found to occasionally contain scattered regions of false ice well outside of the normal extent, caused by wind roughening of the surface. These false signals were eliminated for this study by applying a monthly ocean mask climatology based on passive microwave data to the QuikSCAT fields. The climatology masks eliminate only regions where sea ice should definitely not be found, and thus do not impact the comparison of total ice extent and ice-edge position. The scatterometer fields were also found to exhibit a significant amount of 'noise' along the ice edge. Some of this may be real, but it is likely partly due to variability in the backscatter signal near the edge. To remove some of this noise, fields were filtered with a 5 day centered window. If ice was found in the center day, but not in either of the two days before and after the center day, the ice was assumed to be spurious and was filtered out. Conversely, if ice was not present on the center day but was present during all of the surrounding four days, ice was added to the center day. This procedure also effectively filled occasional gaps in QuikSCAT coverage due to missing swaths. These quality-control measures are similar to those for the SMMR-SSM/I sea-ice product (Cavalieri and others, 1999).

\section{COMPARISON OF PASSIVE MICROWAVE AND SCATTEROMETER SEA-ICE EXTENTS}

Sea-ice extents derived from passive microwave data were compared to the egg and slice scatterometer extents for the period 1999-2004 when QuikSCAT and SSM/I products overlap. Since the QuikSCAT fields in the Arctic cover only regions poleward of $60^{\circ} \mathrm{N}$, the SSM/l fields were subset to 

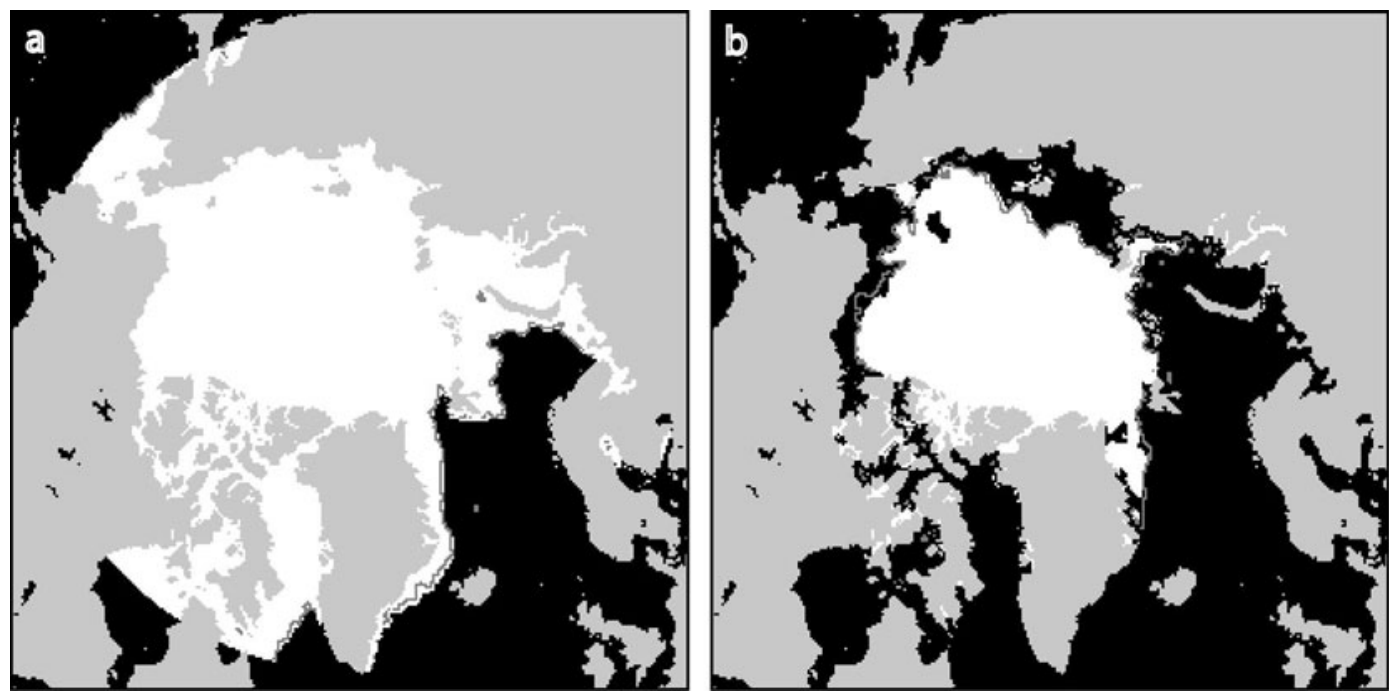

Fig. 2. Arctic sea-ice extent field from SSM/I (white) with a $15 \%$ concentration threshold, overlaid by the QuikSCAT ice-edge contour (dark grey) for (a) winter scene on 1 March 2000, and (b) summer scene on 1 September 2000.

the same spatial domain for comparison. In this paper, we focus on the NASA Team algorithm product from SSM/I, but comparisons using passive microwave extents derived from the Bootstrap algorithm (Comiso and others, 1997) yield similar results.

Previous research (e.g. Comiso and Zwally, 1984) has indicated that the $15 \%$ concentration contour from passive microwave fields corresponds most closely with the average true ice edge. This correspondence is a function primarily of the field-of-view of the sensor and the algorithm characteristics, though it also depends heavily on the character of the ice edge (e.g. whether it is compact vs diffuse), which may change the relationship. Earlier comparisons with the scatterometer ice extent indicated that the 30\% NASA Team concentration contour was most consistent with the scatterometer edge (Remund and Long, 1999). Here we use both the $15 \%$ and $30 \% \mathrm{SSM} / \mathrm{I}$ contours to compare with the QuikSCAT extent.

The QuikSCAT and SSM/I fields both capture the familiar large-scale seasonal cycle in the Arctic and the Antarctic (Fig. 1); results for the year 2000 are presented here for clarity, but other years show similar behavior. During winter, the QuikSCAT extent is lower than the SSM/I extent (Fig. 1a), as has been found in previous comparisons (Remund and Long, 1999). There is better agreement with the 30\% SSM/I contour than with the $15 \% \mathrm{SSM} / \mathrm{I}$ contour, as was also found previously, but the improvement is marginal. Conversely, during summer the $30 \% \mathrm{SSM} / \mathrm{I}$ contour indicates a lower extent than QuikSCAT, while the $15 \%$ contour is in close agreement.

The QuikSCAT slice fields contain more ice than the egg fields and are in closer agreement with the SSM/I extents, but the difference is small compared to the difference of either egg or slice with SSM/I. This is likely because, as discussed above, the egg and slice backscatter fields were processed slightly differently to yield consistent extent estimates.

The time series of the differences (Fig. 1b) clearly demonstrates a seasonality effect in the relative extents, with the egg fields having a lower extent throughout the winter. The egg extent increases relative to SSM/I as the melt season progresses, and yields a higher extent during the late summer, also in agreement with previous comparisons
(Remund and Long, 1999). As discussed above, this seasonality is likely due to the differing emissive and backscatter properties of sea ice during melt and freeze-up. The slice extent difference is smaller than the egg difference, particularly during winter.

The Antarctic fields (Fig. 1a; only the egg field is shown for clarity) have a winter behavior similar to that in the Arctic, with the QuikSCAT extents lower than SSM/I. However, whereas in the Arctic during summer there is close agreement between QuikSCAT and the 15\% SSM/I contour, in the Antarctic the QuikSCAT extent is higher than SSM/I.

Sample images from the Arctic of a winter scene (1 March 2000) and a summer scene (1 September 2000) illustrate the differences between the seasons (Fig. 2). In March, where the QuikSCAT data extend to the ice edge (Baffin Bay, Greenland and Barents Seas), the scatterometer ice edge is consistently within the SSM/I 15\% ice-extent limit. In summer, the situation is more mixed, with the QuikSCAT extent sometimes within (Laptev and East Siberian Seas) the SSM/I extent and in other regions (Beaufort and East Greenland Seas) extending beyond the SSM/I extent.

\section{COMPARISON WITH VISIBLE/INFRARED IMAGERY}

While a comparison between passive microwave and scatterometer extent fields is illuminating, it is limited because it is not clear which field is more representative of the true ice edge. The coarse spatial resolution of the raw sensor data $(25-75 \mathrm{~km})$ clearly limits how well the sensors can resolve the ice-edge position. The resolution-enhanced QuikSCAT product has the potential to obtain substantially improved ice-edge locations, but until now this has not been verified. Here we compare SSM/I and the enhancedresolution QuikSCAT products with Advanced Very High Resolution Radiometer (AVHRR) imagery to evaluate the accuracy of the ice-edge estimates. For this comparison, the QuikSCAT edge is not temporally filtered (with the 5 day window), but the passive microwave ocean mask is applied.

The AVHRR data have been used in a previous study to evaluate the quality of passive microwave concentrations (Meier, 2005). The data encompass the period June 2001March 2002 in three regions: Baffin Bay, the East Greenland 
Table 1. Statistics of ice-edge comparison with AVHRR imagery for the six case studies. The 'Edge' row briefly describes the character of the ice edge in the AVHRR image as diffuse or compact. The '\# pixels' refers to the number of AVHRR pixels used to calculate the statistics

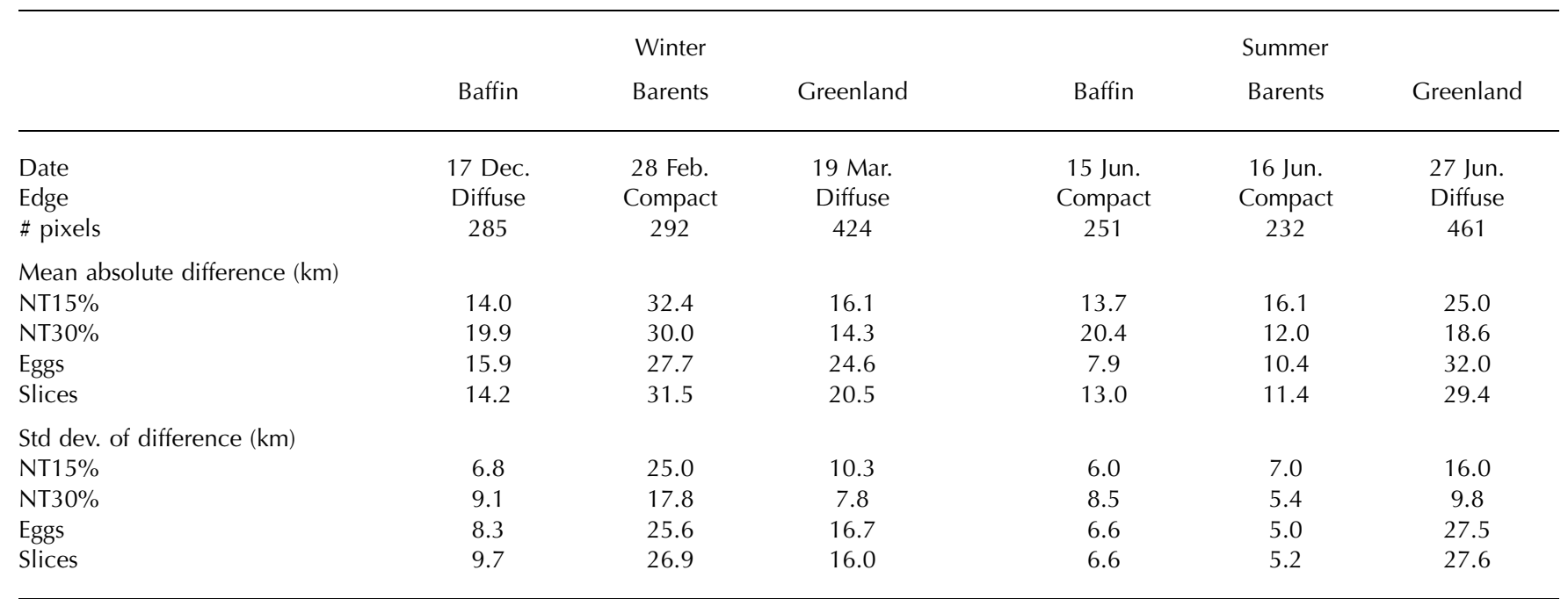

Sea and the Barents Sea. The AVHRR data are gridded to a $2.5 \mathrm{~km}$ spatial resolution on the NSIDC polar stereographic grid, consistent with the SSM/I and QuikSCAT fields. The nadir resolution of AVHRR is $1.1 \mathrm{~km}$. Thus most cells in the $2.5 \mathrm{~km}$ grid are oversampled, though because resolution decreases off-nadir, cells near the edge of a swath may be interpolated. While higher-resolution products are available for comparison (e.g. moderate-resolution imaging spectroradiometer (MODIS), RADARSAT), the AVHRR scenes employed here are useful because the gridded resolution is at roughly the same spatial scale as the enhancedresolution scatterometer data, allowing a near pixel-to-pixel comparison.

Six scenes, one from each region for both summer (using AVHRR channel 2, visible/near infrared) and winter (using AVHRR channel 4, thermal infrared), were selected based on the amount of clear sky in the images and the clarity of the ice edge. The edge location was determined through manual selection using the ENVI image-processing software package. Care was taken to select edge pixels that were free of obvious cloud cover and in which an ice edge could be clearly delineated (i.e. high contrast between ice and water in the images). However, in some scenes the ice edge was diffuse, resulting in some subjectivity in the selection of the 'true' ice edge. The distance between AVHRR and microwave ice edge was computed based on the great circle distance between the AVHRR edge pixel and the nearest SSM/I scatterometer edge pixel, based on the center latitude and longitude coordinates of each pixel.

Comparison with the AVHRR edge (Table 1) indicates that at times QuikSCAT does provide a much more precise edge location (e.g. in the Baffin and Barents summer cases). However, overall, the results are mixed. Often, the SSM/I edge is comparable to, or even substantially better (i.e. Greenland winter) than, the QuikSCAT edge. There also does not seem to be a significant advantage to using slice fields over egg fields, despite the higher effective spatial resolution; this again is probably because the QuikSCAT extent algorithm was tuned to obtain consistent extent estimates from both egg and slice fields. The standard deviation of the differences in the QuikSCAT fields is often higher than SSM/I. This is likely due to the nature of the QuikSCAT data, where the resolution-enhancement algorithm sacrifices smoothness in the fields for greater spatial resolution, resulting in a 'noisier' ice edge.

There does not appear to be any particular seasonality in the difference values (e.g. the Barents region in winter has higher differences than in summer, but the situation is reversed for the Greenland and Baffin regions). There also does not appear to be any direct correlation between the difference values and the ice-edge character (diffuse or compact).

In examining the AVHRR imagery and ice-edge locations (Fig. 3), it is apparent that local conditions are the likely cause of the variation in the difference values. In the Barents winter scene (Fig. 3a), while the ice edge is reasonably compact, it is clear that there is a strong off-ice wind, indicated by the parallel cloud streaks starting from just off the edge. Thus, the ice edge is likely quite dynamic on this day. The AVHRR image provides a 'snapshot' of the ice-edge location at a specific time of the day. The SSM/I and QuikSCAT fields are derived from average images composited from several swaths over 24-36 hours and can only provide a daily average iceedge location. Over such a long interval under strong wind conditions, the ice dynamics may move the edge several kilometers, potentially resulting in a large difference between the instantaneous and the daily average ice-edge location. Ice motions of $30-50 \mathrm{~km} \mathrm{~d}^{-1}$ are not unusual in Fram Strait and on the east coast of Greenland (e.g. Kwok and others, 1998), resulting in a displacement of one to two SSM/I and several enhanced scatterometer pixels compared to an instantaneous AVHRR pixel location. In addition, the sensible- and latent-heat fluxes under such conditions may yield relatively rapid growth of new ice, substantially extending the ice edge over 24-36 hours. In contrast to the Barents winter situation, in the summer Barents scene (Fig. 3b) the conditions appear relatively calm, the ice edge is very compact, and there is no ice growth during summer, so the instantaneous AVHRR edge is more representative of the QuikSCAT and SSM/I daily average edge.

The large differences in the East Greenland Sea are likely attributable to similar factors. It is a region of fast ice motion (ice flowing through Fram Strait) and a highly variable ice edge, which is evident in both the summer and winter 
Greenland scenes (not shown). While Baffin Bay can also experience quite variable ice-edge conditions, the Baffin scenes (not shown) reveal what appear to be more stable ice edges, even in the relatively diffuse edge of the winter scene.

There are some important caveats to note regarding these comparisons with AVHRR. First, the 'mean absolute difference' of the ice edge is calculated. In other words, regardless of whether the ice edge is overestimated or underestimated, it is simply recorded as a positive difference. So unless there is a persistent bias, the arithmetic mean ice-edge position difference (averaging overestimates with underestimates) would be smaller. Computing the simple mean difference is a more standard comparison, but absolute difference is more relevant operationally. For the pilot of a ship operating near an ice-infested region, the fact that the edge may be overestimated by several kilometers at certain times and underestimated by several kilometers at other times is more pertinent information than the fact that the average uncertainty in the ice-edge location may be small.

There is also error in the ice edge derived from the AVHRR images: in geo-registration, in the detection of ice and, most importantly, in the manual selection of the iceedge locations. As noted above, care was taken in the selection of the AVHRR edge pixels, but some scenes contained a fairly diffuse edge (as noted in Table 1), making selection somewhat subjective. However, the ice-edge statistics do not seem biased due to the type of ice edge (e.g. Baffin Bay has good agreement with AVHRR in both diffuse and compact conditions, and Barents Sea has differing agreement with AVHRR even though both scenes have a fairly compact ice edge).

\section{CONCLUSION}

Scatterometer and passive microwave fields provide complete coverage over the Arctic and Antarctic in all sky conditions, greatly improving coverage over visible/infrared and SAR sensors, but at a much lower spatial resolution, limiting their usefulness for precise determination of the ice edge. Enhanced-resolution QuikSCAT scatterometer sea-ice extent fields provide significantly improved spatial resolution over standard SSM/I passive microwave data, but at the cost of higher noise. Thus the resolution-enhanced QuikSCAT fields have the potential to obtain a better ice edge than from the lower-resolution SSM/I fields. However, the results here indicate that there is not consistent improvement and the relative performance of the fields likely depends substantially on local ice-edge conditions (e.g. whether the edge is diffuse or compact, how much it varies during the 24-36hour period over which the QuikSCAT and SSM/I fields are compiled). The higher noise level in the enhanced QuikSCAT fields may also offset some of the gain from the finer spatial resolution.

There are also several pathways being investigated to improve the utility of passive microwave data for ice-edge detection. The resolution enhancement technique developed for scatterometers has now been applied to SSM/I brightness temperature fields (Long and Daum, 1998), though sea-ice concentration/extent fields from these brightness temperatures have not yet been evaluated. Other resolution-enhancement techniques have also been applied to SSM/I data to improve ice-edge determination (Hunewinkel and others, 1998) and polynya detection (Markus and Burns, 1995).
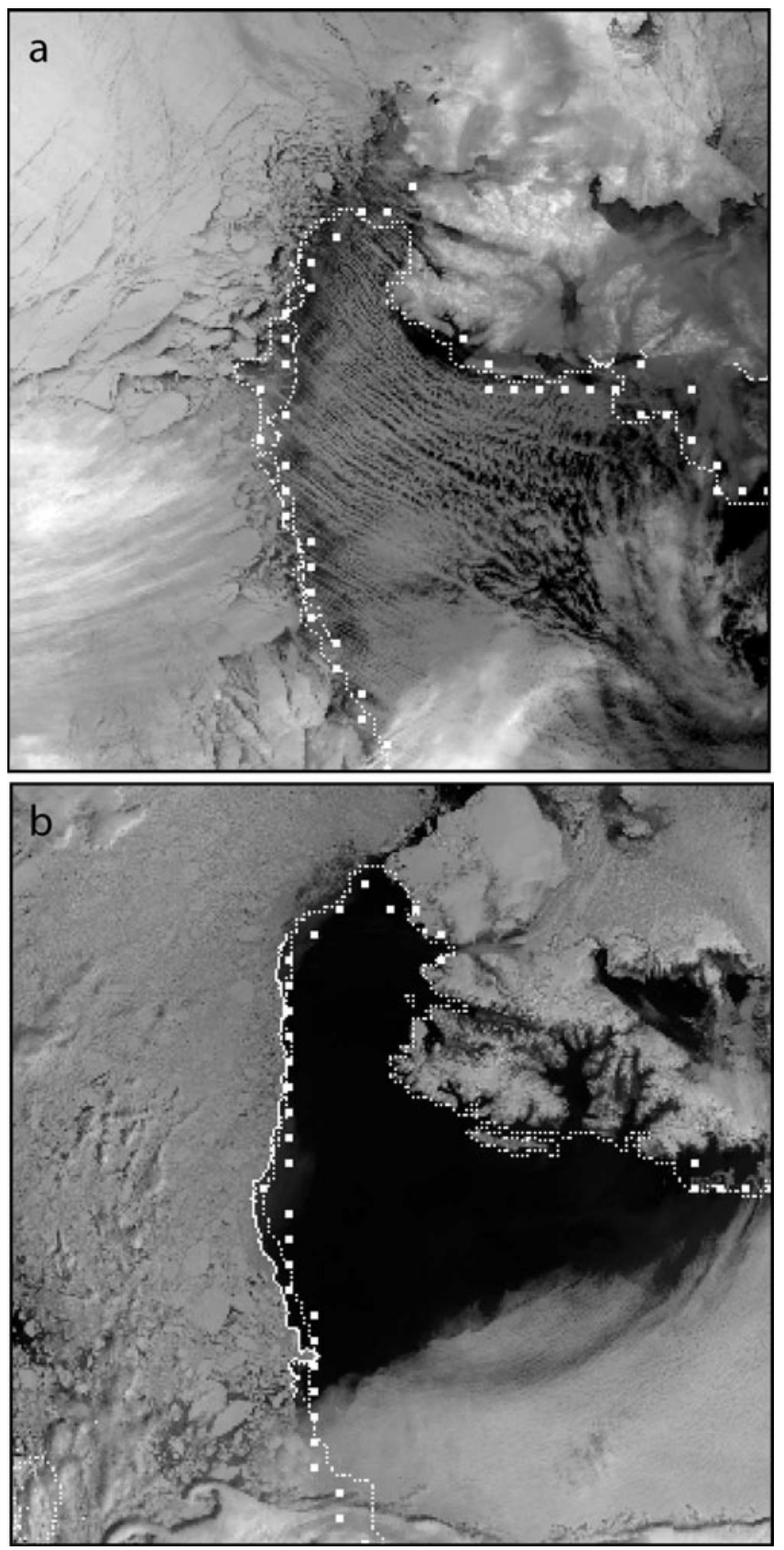

Fig. 3. AVHRR image for (a) winter scene on 28 February 2002 and (b) summer scene (16 June 2001). AVHRR ice edge is outlined in small dense white dots; QuikSCAT (eggs) ice edge is in small sparser white dots; SSM/I ice edge (15\% contour) is in large white dots. North is roughly to the left; Svalbard is in the upper right.

The newest passive microwave instrument, NASA's Advanced Microwave Scanning Radiometer for EOS (Earth Observing System) (AMSR-E), represents a significant improvement over SSM/I. AMSR-E has a field-of-view with more than double the spatial resolution of SSM/I, as well as improved sea-ice algorithms (Markus and Cavalieri, 2000; Comiso and others, 2003). Initial evaluation of the AMSR-E ice edge shows improved accuracy (Heinrichs and others, 2006) over SSM/I. Passive microwave sea-ice algorithms that rely on high-frequency channels (85-90 GHz) (e.g. Kern and Heygster, 2001) provide even greater spatial resolution that, particularly for AMSR-E $(6.25 \mathrm{~km}$ gridded), rival or exceed the effective spatial resolution of the enhanced QuikSCAT fields, but without the higher noise. However, the 
high-frequency SSM/I and AMSR-E channels are susceptible to atmospheric interference, particularly near the ice edge.

Current standard resolution passive microwave and scatterometer sea-ice fields do not meet operational ice analysis requirements to provide the ice-edge location with an uncertainty of $<10 \mathrm{~km}$ (Partington, 2000). While the resolution-enhanced scatterometer clearly has some benefit in ice-edge detection, a blended product combining both scatterometer and passive microwave data will result in further improvements that perhaps meet the operational criterion and provide an accurate, complete, daily ice-extent and ice-edge field suitable for operational and climate applications.

\section{ACKNOWLEDGEMENTS}

QuikSCAT ice-extent fields are courtesy of D.G. Long at BYU, generated by the Scatterometer Climate Record Pathfinder project from data obtained from the Physical Oceanography Distributed Active Archive Center (PO.DAAC). AVHRR data were obtained from the Danish Meteorological Institute (thanks to S. Andersen for assistance). J. Smith (NSIDC) assisted in processing of scatterometer data. This work was completed under NASA grant No. NNG04GG72A.

\section{REFERENCES}

Cavalieri, D.J., P. Gloersen and W.J. Campbell. 1984. Determination of sea ice parameters with the NIMBUS 7 SMMR. J. Geophys. Res., 89(D4), 5355-5369.

Cavalieri, D.J., C.L. Parkinson, P. Gloersen, J.C. Comiso and H.J. Zwally. 1999. Deriving long-term time series of sea ice cover from satellite passive-microwave multisensor data sets. J. Geophys. Res., 104(C7), 15,803-15,814.

Comiso, J.C. and H.J. Zwally. 1984. Concentration gradients and growth/decay characteristics of the seasonal sea ice cover. J. Geophys. Res., 89(C5), 8081-8103.

Comiso, J.C., D.J. Cavalieri, C.L. Parkinson and P. Gloersen. 1997. Passive microwave algorithms for sea ice concentration: a comparison of two techniques. Remote Sens. Environ., 60(3), 357-384.

Comiso, J.C., D.J. Cavalieri and T. Markus. 2003. Sea ice concentration, ice temperature, and snow depth using AMSR-E data. IEEE Trans. Geosci. Remote Sens., 41(2), 243-252.

Early, D.S. and D.G. Long. 2001. Image reconstruction and enhanced resolution imaging from irregular samples. IEEE Trans. Geosci. Remote Sens., 39(2), 291-302.
Eppler, D.T. and 14 others. 1992. Passive microwave signatures of sea ice. In Carsey, F.D. and 7 others, eds. Microwave remote sensing of sea ice. Washington, DC, American Geophysical Union, 47-71. (Geophysical Monograph Series 68.)

Heinrichs, J.F., D.J. Cavalieri and T. Markus. 2006. Assessment of the AMSR-E sea ice concentration product at the ice edge using RADARSAT- 1 and MODIS imagery. IEEE Trans. Geosci. Remote Sens., 44(11), 3070-3080.

Hunewinkel, T., T. Markus and G.C. Heygster. 1998. Improved determination of the sea ice edge with SSM/I data for small-scale analyses. IEEE Trans. Geosci. Remote Sens., 36(5), 1795-1808.

Kern, S. and G. Heygster. 2001. Sea-ice concentration retrieval in the Antarctic based on the SSM/I $85.5 \mathrm{GHz}$ polarization. Ann. Glaciol., 33, 109-114.

Kwok, R., A. Schweiger, D.A. Rothrock, S. Pang and C. Kottmeier. 1998. Sea ice motion from satellite passive microwave imagery assessed with ERS SAR and buoy motions. J. Geophys. Res., 103(C4), 8191-8214.

Long, D.G. and D.L. Daum. 1998. Spatial resolution enhancement of SSM/I data. IEEE Trans. Geosci. Remote Sens., 36(2), 407-417.

Long, D.G., P.J. Hardin and P.T. Whiting. 1993. Resolution enhancement of spaceborne scatterometer data. IEEE Trans. Geosci. Remote Sens., 31(3), 700-715.

Markus, T. and B.A. Burns. 1995. A method to estimate sub-pixelscale coastal polynyas with satellite passive microwave data. J. Geophys. Res., 100(C3), 4473-4487.

Markus, T. and D.J. Cavalieri. 2000. An enhancement of the NASA Team sea ice algorithm. IEEE Trans. Geosci. Remote Sens., 38(3), 1387-1398.

Meier, W.N. 2005. Comparison of passive microwave ice concentration algorithm retrievals with AVHRR imagery in Arctic peripheral seas. IEEE Trans. Geosci. Remote Sens., 43(6), 1324-1337.

Onstott, R.G. 1992. SAR and scatterometer signatures of sea ice. In Carsey, F.D. and 7 others, eds. Microwave remote sensing of sea ice. Washington, DC, American Geophysical Union, 73-104. (Geophysical Monograph Series 68.)

Partington, K.C. 2000. A data fusion algorithm for mapping sea-ice concentrations from Special Sensor Microwave/Imager data. IEEE Trans. Geosci. Remote Sens., 38(4), 1947-1958.

Remund, Q.P. and D.G. Long. 1999. Sea ice extent mapping using Ku band scatterometer data. J. Geophys. Res., 104(C5), 11,51511,527 .

Remund, Q.P. and D.G. Long. 2000. Iterative estimation of Antarctic sea ice extent using SeaWinds data. In IGARSS 2000, 20th International Geoscience and Remote Sensing Symposium, 24-28 July 2000, Honolulu, Hawaii, USA. Proceedings, Vol. 2. Piscataway, NJ, Institute of Electrical and Electronics Engineers, 491-493. 